\title{
Ultrastructural Features of the Midgut Epithelium of Females Lutzomyia intermedia (Lutz \& Neiva, 1912) (Diptera: Psychodidae: Phlebotominae)
}

\author{
Cláudia A Andrade-Coêlho/ ${ }^{+}$, Jacenir Santos-Mallet, Nataly A Souza, \\ Ulisses Lins*, Maria Nazareth L Meirelles**, Elizabeth F Rangel
}

Departamento de Entomologia **Departamento de Ultraestrutura e Biologia Celular, Instituto Oswaldo CruzFiocruz, Av. Brasil 4365, 21045-900 Rio de Janeiro, RJ, Brasil *Departamento de Microbiologia Geral, Instituto de Microbiologia Professor Paulo de Góes, Universidade Federal do Rio de Janeiro, Rio de Janeiro, RJ, Brasil

A morphological study of the midgut of Lutzomyia intermedia, the primary vector of cutaneous leishmaniasis, in southeast Brazil, was conducted by light, scanning and transmission electron microscopy. The midgut is formed by a layer of epithelium of columnar cells on a non-cellular basal lamina, under which there is a musculature, which consists of circular and longitudinal muscular fibers. A tracheolar network is observed surrounding and penetrating in the musculature. Females were examined 12, 24, 48, $72 \mathrm{~h}$ and 5 days following a blood meal and were analyzed comparatively by transmission electron microscopy with starved females. In starved females, the epithelium of both the anterior and posterior sections of the midgut present whorl shaped rough endoplasmic reticulum. The posterior section does not present well-developed cellular structures such as mitochondria. Observations performed at 12, 24, 48 and $72 \mathrm{~h}$ after the blood meal showed morphological changes in the cellular structures in this section, and the presence of the peritrophic matrix up to $48 \mathrm{~h}$ after the blood meal. Digestion is almost complete and a few residues are detected in the lumen $72 \mathrm{~h}$ after blood feeding. Finally, on the 5th day after the blood meal all cellular structures present the original feature resembling that seen in starved sand flies. Morphometric data confirmed the morphological observations. Mitochondria, nuclei and microvilli of midgut epithelial cells are different in starved and blood fed females. The mitochondria present a similar profile in the epithelium of both the anterior and posterior section of the midgut, with higher dimension in starved females. The cell microvilli in the posterior section of the midgut of starved females are twice the size of those that had taken a blood meal. We concluded that there are changes in the midgut cellular structures of L. intermedia during the digestion of blood, which are in agreement with those described for other hematophagous diptera.

Key words: midgut - ultrastructure - Lutzomyia intermedia - Phlebotominae

Since the beginning of the century (Aragão 1922) Lutzomyia (Nyssomyia) intermedia has beem considered as vector of cutaneous leishmaniasis due to Leishmania (Viannia) braziliensis in southeast Brazil, according to ecological and experimental studies (Forattini \& Santos 1952, Forattini et al. 1972, Forattini 1973, Rangel et al. 1984, 1990, 1992).

In order to improve our understanding of the Leishmania - sand fly vector interaction associated to the susceptibility of sand fly species to the parasite - or to elucidate some taxonomic aspects of Leishmania, some studies have been performed

\footnotetext{
This reseach was supported by Fiocruz and CNPq, Brazil, and forms part of the first author's MSc thesis. ${ }^{+}$Corresponding author. Fax: +55-21-2290 9339. E-mail: andrade@gene.dbbm.fiocruz.br Received 26 de September 2000 Accepted 16 August 2001
}

related to the morphology of the midgut of female sand flies and the formation of peritrophic matrix, some of them in specimens experimentally infected by Leishmania spp. (Adler \& Theodor 1926, Davis 1967, Gemetchu 1974, Molyneux et al. 1975, Rundin \& Hecker 1982, Warburg et al. 1986, Walters et al. 1987, Blackburn et al. 1988, Killick-Kendrick et al. 1988, Walters et al. 1989a,b, Billigsley 1990, Elnaiem et al. 1992, Walters et al. 1992, Walters 1993, Elnaiem et al. 1994).

In this paper, we studied the fine structure of the epithelium of the midgut of L. intermedia, under light, scanning and transmission electron microscopy. The morphological studies on the midgut epithelium of $L$. intermedia females may be useful for future investigations on the $L$. (V.) braziliensis-L. (N.) intermedia relationship because they may provide a structural framework for physiological interpretations of the processes involved in this relationship. 


\section{MATERIALS AND METHODS}

Study sample - Field specimens of L. intermedia were collected in the Pontões District, Afonso Cláudio county, State of Espírito Santo, and reared according to the method proposed by Rangel et al. (1985) in the insect breeding facility at the Leishmaniasis Vector Laboratory, Entomology Department, Oswaldo Cruz Institute-Fiocruz, Rio de Janeiro, Brazil.

Females which had been starved and others which were sampled, 12, 24, 48, $72 \mathrm{~h}$ and 5 days after a blood meal were anesthetized with $\mathrm{CO}_{2}$, kept on ice and transferred individually to slides with a drop of saline solution; the digestive tract was dissected and the principal tomes of the digestive tube were examined using scanning and transmission electron microscopy techniques.

Scanning electron microscopy (SEM) - Following dissection, the digestive tracts of unfed females were fixed in $2.5 \%$ glutaraldehyde in $0.1 \mathrm{M}$ cacodylate buffer ( $\mathrm{pH} 7.2$ ) containing $3.5 \%$ sacarose, for $1 \mathrm{~h}$ at room temperature, washed three times in the same buffer for 15 min each time, post-fixed in buffered $1 \%$ osmium tetroxide (Angermüller \& Fahimi 1982) for $1 \mathrm{~h}$ at room temperature, washed three times in cacodylate buffer for 10 min each time. Tracts were then dehydrated in acetone series $[7.5 \%, 15 \%, 30 \%, 50 \%, 70 \%, 90 \%$ and $100 \%(3 x)$ for 10 min each time], critical point dried using $\mathrm{CO}_{2}$ in a Balzers apparatus. Sputtered samples were observed on a Zeiss DSM 940 SEM.

Transmission electron microscopy (TEM) - The midgut of starved and blood feed females were studied. Immediately after dissection, the midgut was cut away from the rest of the digestive tract with the help of entomological stylets, separating it at the anterior section (at the level of the esophagus) and posterior section (at the level of the insertion of the Malpighian tubules).

The procedure was the same as described above, dehydrated in acetone series and embedded in epoxy resin (Epon). Semi-thin $(1 \mu)$ sections were obtained, stained with methylene blue and basic fuchsin and observed under a Zeiss Axioplan microscope. Ultrathin sections (50 to $80 \mathrm{~nm}$ thick) were collected in collodium coated copper grids and contrasted in 5\% uranyl acetate in total darkness for 20 to $30 \mathrm{~min}$ followed by staining in filtered $2 \%$ lead citrate (Reynolds 1963) for 5 min. Grids were observed on a Zeiss EM-10 TEM.

Morphometric evaluation - Midgut of the unfed females and those sampled $12 \mathrm{~h}$ after a blood meal were studied. Microphotographs of anterior and posterior sections of the midgut were scanned and measured using a KS 400 image analysis system (Kontron Eletronik). Magnification calibration was done with a calibration grid replicate pattern (Ted Pela, Inc. CAT\# 603) and the following morphometric parameters were evaluated: (a) area of the object; (b) major axis, corresponding to the longest line that can be drawn through the object; (c) minor axis, corresponding to the longest line that can be drawn through the object while maintaining perpendicularity with the major axis. Profiles of the microvilli, mitochondria and nucleus were traced manually on the digitized images and the morphometric parameters calculated by the system.

\section{RESULTS}

$S E M$ - Fig. 1 shows the anterior and posterior sections of the midgut of $L$. intermedia and the region where it connects to the hindgut, matching with the point of insertion of the Malpighian tubules, at the beginning of which we see a thin section of the hindgut called ileum or colon. We observed muscular layers, consisting of circular and longitudinal muscle fibers along the length of the digestive tube.

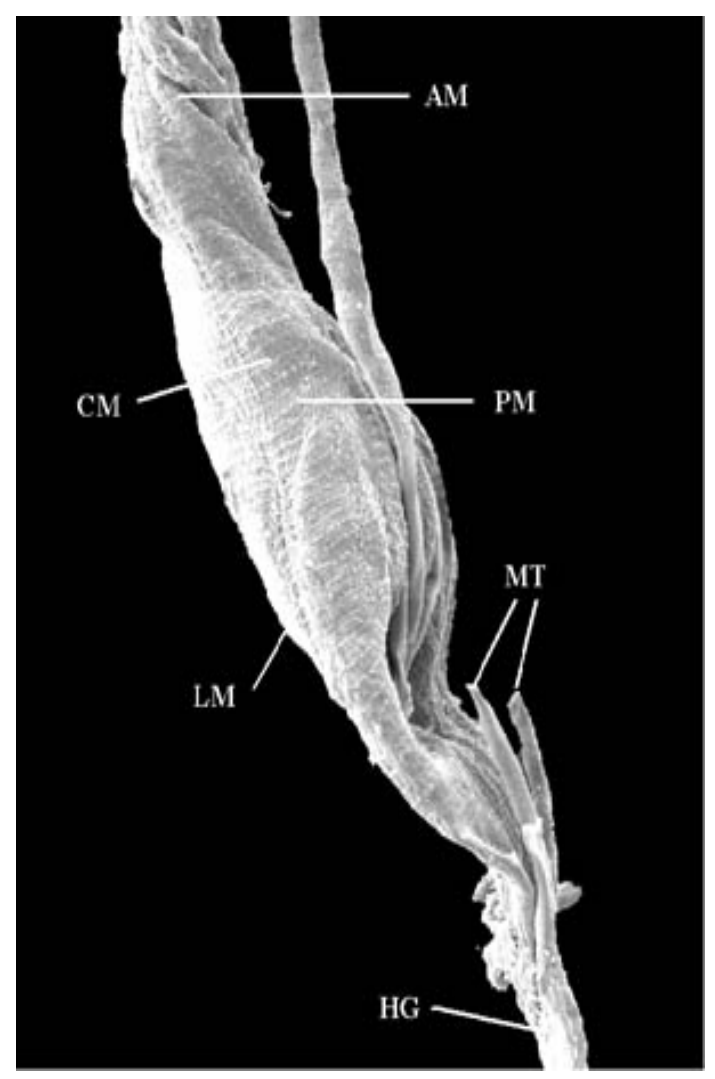

Fig. 1: scanning electron microscope images of midgut regions of Lutzomyia intermedia female after emergence: anterior midgut (AM), posterior midgut (PM), Malpighian tubules (MT), hindgut (HG), circular muscle (CM) and longitudinal muscle (LM) (x 5,000) 
TEM - In unfed females, the inner part of the midgut was lined with an epithelium consisting of a single continuous layer of columnar cells, generally with oval-shaped and quite evident nuclei (Fig. 2). Immediately after it emerges, the apical region of the epithelium in the anterior section of the midgut which in L. intermedia females displays parallel microvilli, mitochondria throughout the cytoplasm, a more or less central and rounded nucleus, and clear basal labyrinths, inside which we found some mitochondria. Below this we found a thin, continuous basal membrane. We also observed the presence of the septate junction, which extends from the apical region until approximately the median region of the cell (Fig. 3). The most striking characteristic at this point is the presence of the whorled rough endoplasmatic reticulum (Figs 3, 4). Lipid inclusions are observed in the apical region of the cells, as well as vesicles containing non-electrondense material, while the cytoplasm in the apical region is more electron-dense than in the rest of the cell, and the amount of the whorled form of rough endoplasmatic reticulum is considerably increased (Fig. 4).

The posterior section of the midgut (Figs 5a, b) displays microvilli arranged in parallel and the whorled form of rough endoplasmatic reticulum, although in a smaller amount when compared to the anterior section. In the cytoplasm we observed vacuoles with various contents, ranging from completely electron-dense to electron-lucid; the basal membrane has a continuous shape in some areas (Fig. 5a), while in others it is undulated (Fig. 5b).

12 hours after bloodmeal - The whorled form of the rough endoplasmatic reticulum in the epithelial cells along the entire midgut was no longer observed. The mitochondria, although dispersed in other portions of the cytoplasm, are found in groups close to the basal region. At this stage of blood digestion, the basal labyrinth is made up of larger spaces (Fig. 6).
In the posterior section, the presence of the peritrophic matrix completely surrounding the alimentary bolus is clearly noted. At this stage, a characteristic electron-lucid line surrounding the microvilli throughout their entire length may be seen. Higher up, towards the lumen, we find a large line called the electron-lucid space. The mitochondria

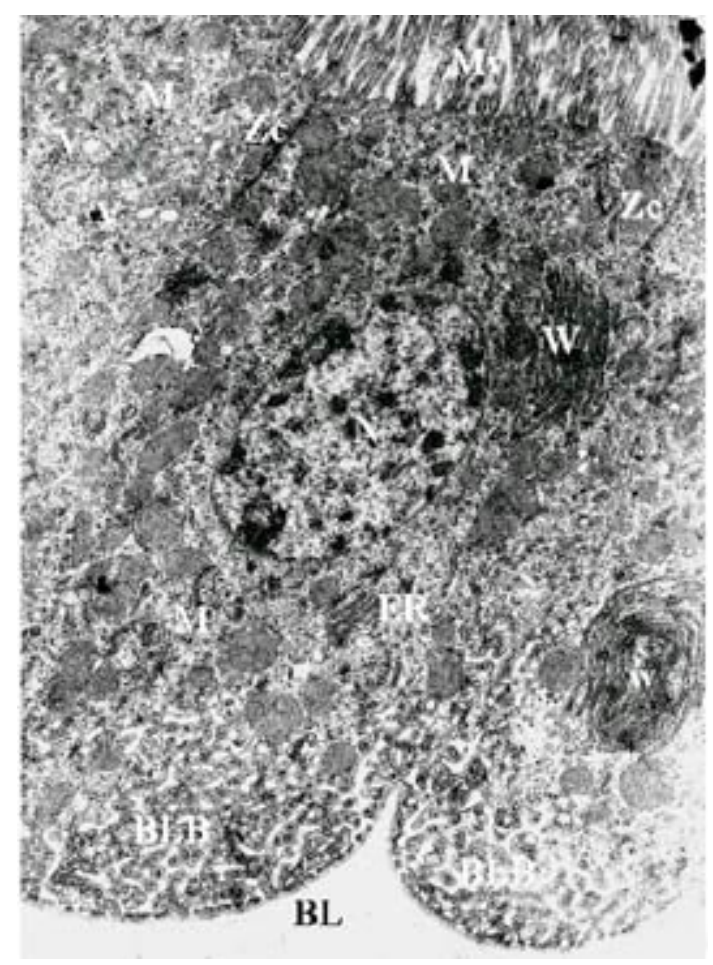

Fig. 3: electron micrograph of a longitudinal section of the anterior midgut region of a Lutzomyia intermedia female, after emergence showing the microvilli $(\mathrm{Mv})$, nucleus $(\mathrm{N})$, mitochondria $(\mathrm{M})$, zonula continua $(\mathrm{Zc})$, basal labyrinth (BLB), basal lamina (BL), vacuoles (v), ribosomes (r). The granular endoplasmic reticulum (ER) is, characteristic of the blood-starved sand fly, arranged in whorls (W) $(x$ 3,000)

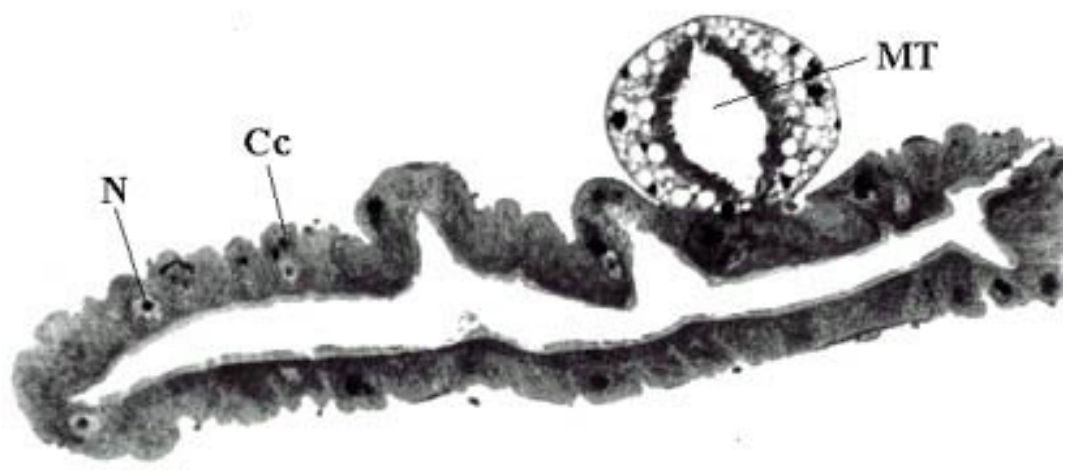

Fig. 2: longitudinal section of midgut region after emergence of Lutzomyia intermedia female showing colunar cells (Cc), nucleus (N) and Malpighian tubules (MT) (x 5,500) 
are located mainly in the apical region of the cell. The spaces in the basal labyrinth are clearly expanded. Lipid inclusions are seen in the basal region. The rough endoplasmatic reticulum is not

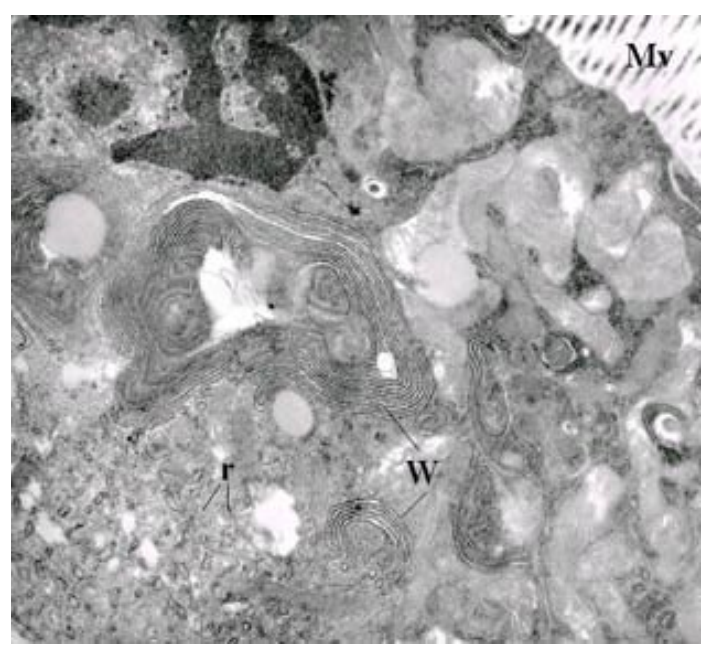

Fig. 4: electron micrograph of a transverse section of the anterior midgut region of a Lutzomyia intermedia female, after emergence; microvilli (Mv), whorls (W), ribosomes (r) $\left(\begin{array}{ll}x & 2,100)\end{array}\right.$
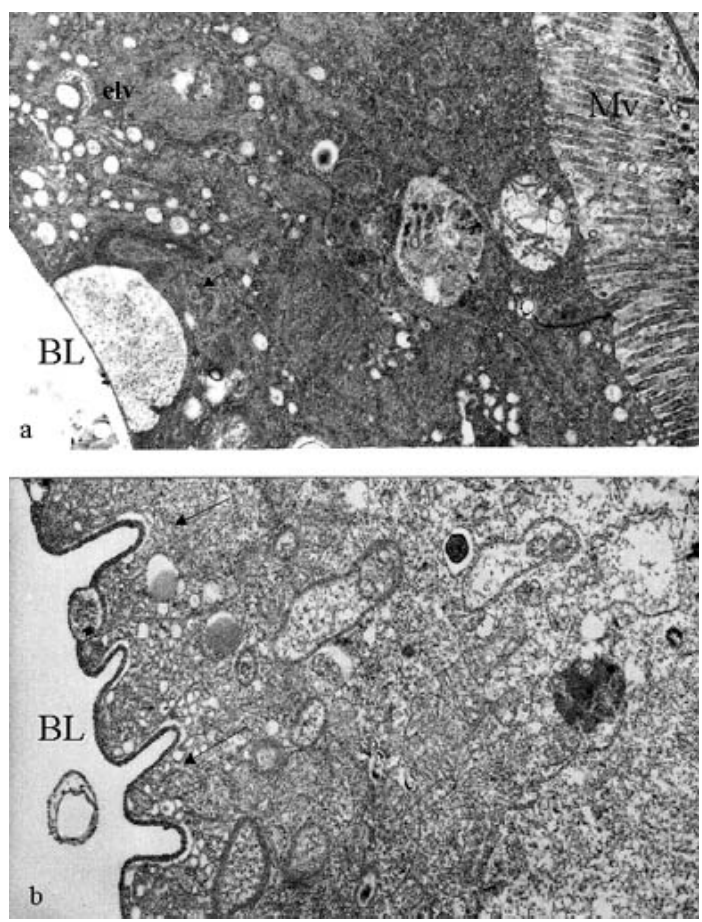

Figs 5a, b: electron micrograph of a transverse section of the posterior midgut region of Lutzomyia intermedia female, after emergence showing electron-lucent vacuoles (elv), microvilli (Mv). Not observed the basal labyrinth somewhere regions $(\rightarrow)$ in the basal lamina (BL) (x 2,100 and $\mathrm{x} 2,400$ )

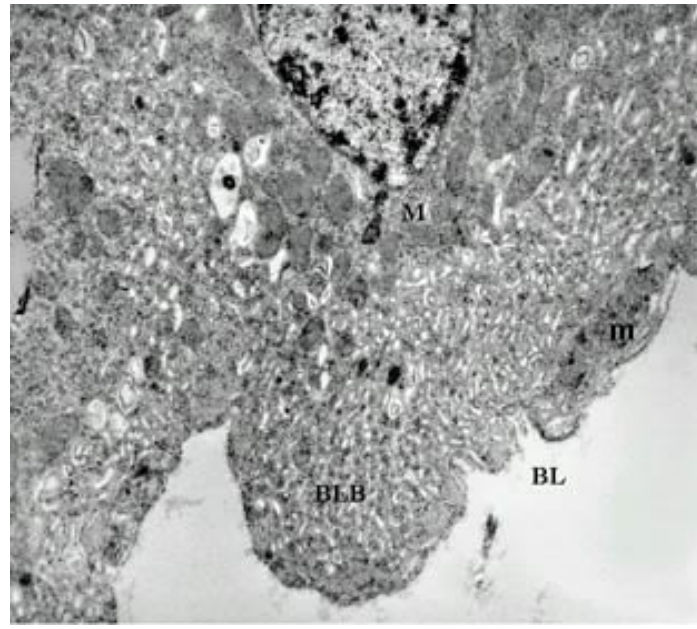

Fig. 6: electron micrograph of a longitudinal section of the anterior midgut region of Lutzomyia intermedia female, $12 \mathrm{~h}$ after bloodmeal showing abundant mitochondria (M) near the nucleus $(\mathrm{N})$, basal labyrinth (BLB), basal lamina (BL) and muscle (m) (x 2,100)

whorled, and gives rise to dispersed elongated branches. In the apical region, the continuous zonule is extremely electron-dense, with numerous profiles of microvilli (Fig. 7).

24 hours after bloodmeal - Numerous lipid inclusions in the cells of the anterior section of the midgut were observed, occupying over half of the cytoplasm, some of them displaying electron-dense content at periphery (Fig. 8). At this stage, the posterior section of the midgut has the space between the microvilli filled with secretions and products of blood digestion. We observed lipid inclusions with a continuous electron-dense line on their surface. This section also shows an abundant rough endoplasmatic reticulum spread throughout the cytoplasm and mitochondria right under the microvilli (Fig. 9).

48 hours after bloodmeal - The epithelium anterior section shows cells from the non-whorled rough endoplasmatic reticulum and mitochondria distributed throughout the cytoplasm. Lipid inclusions can also be observed. In the basal region, immediately under the columnar cells, we observe small cells with large, slightly oval nuclei, occupying nearly all of the cytoplasm (Fig. 10). In the posterior section, the peritrophic matrix is present, generally with a wider electron-lucid space (Fig. 11b) than $12 \mathrm{~h}$ after the bloodmeal. We observed a cell containing clear vacuoles spread around the cytoplasm and especially surrounding the nucleus, which is large and rounded, with chromatin located mainly on the periphery (Fig. 11a). 
72 hours after bloodmeal - The epithelial cells in the anterior section display clear vacuoles located in the apical region, granules with slightly electron-dense content, and lipid inclusions. No basal labyrinths were seen (Fig. 12). In the lumen of the posterior section, we only observed residual blood, and the peritrophic matrix no longer ap-

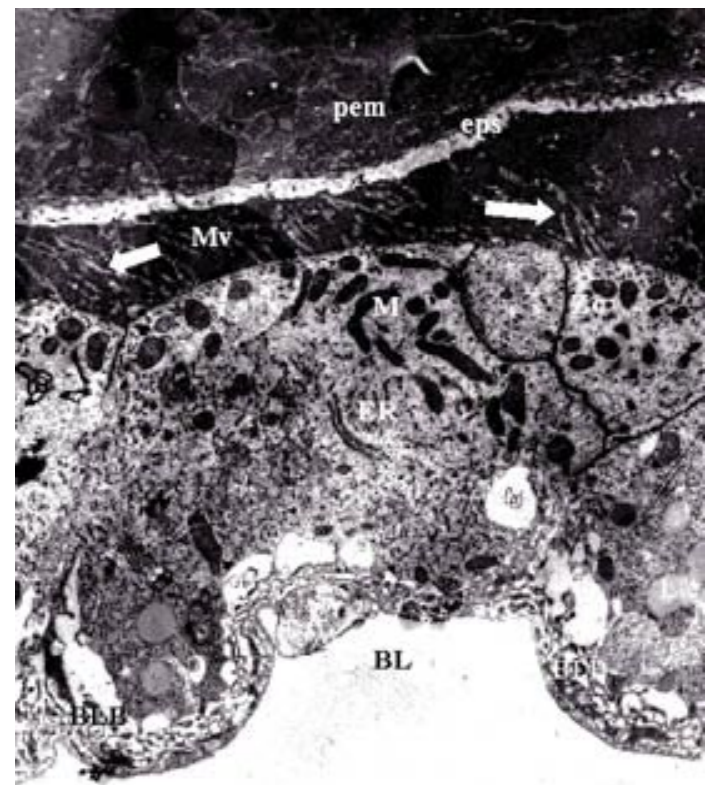

Fig. 7: electron micrograph of a longitudinal section of the posterior midgut region of Lutzomyia intermedia female, $12 \mathrm{~h}$ after bloodmeal showing the peritrophic matrix (pem), ectoperitrophic space (eps), secretion of electron-lucid components from microvilli (Mv), mitochondria (M), zonula continua $(\mathrm{Zc})$, endoplasmic reticulum (ER), lipidics inclusions (L), basal labyrinth (BLB) and basal lamina (BL) (x 2,800)

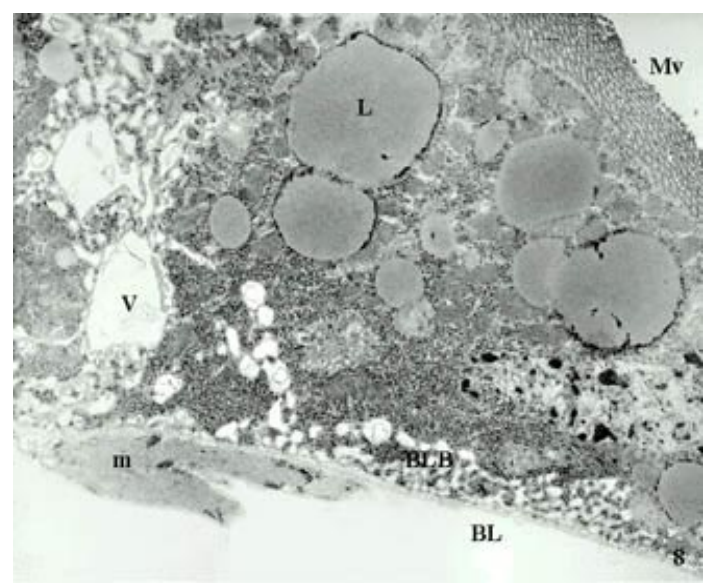

Fig. 8: electron micrograph of a transverse section of the anterior midgut region of Lutzomyia intermedia female, $24 \mathrm{~h}$ after bloodmeal showing the vacuoles (v), lipidic inclusions (L), muscle (m), basal labyrinth (BLB), microvilli $(\mathrm{Mv})$ and basal lamina (BL) (x 2,100)

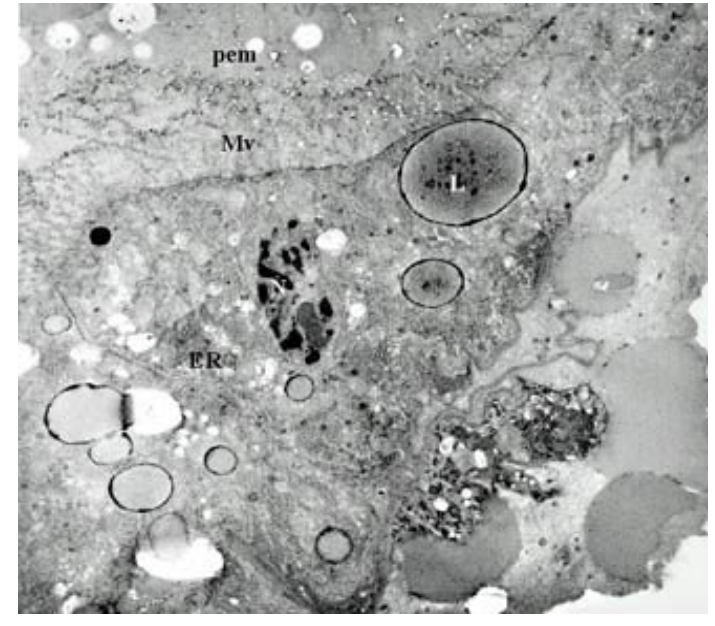

Fig. 9: electron micrograph of a transverse section of the posterior midgut region of Lutzomyia intermedia female, $24 \mathrm{~h}$ after bloodmeal showing the peritrophic matrix (pem), microvilli (Mv). Score electron-dense around the lipidics inclusions (L), endoplasmic reticulum (ER) and nucleus (N) (x 2,000)

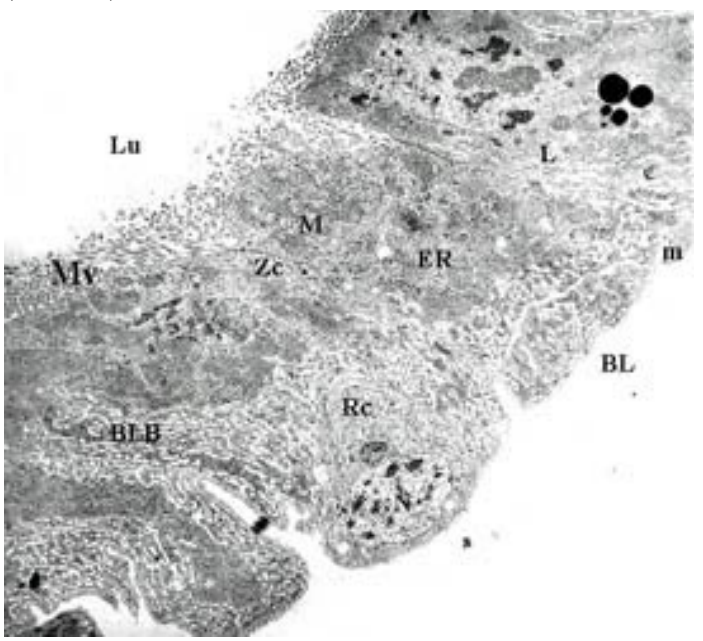

Fig. 10: electron micrograph of a transverse section of the anterior midgut region of Lutzomyia intermedia female, $48 \mathrm{~h}$ after bloodmeal showing the lumen (Lu), microvilli $(\mathrm{Mv})$, mitochondria $(\mathrm{M})$, zonula continua $(\mathrm{Zc})$, numerous endoplasmic reticulum (ER) everywhere the citoplasm, lipidics inclusions (L) in the group near the labyrinths basais (BLB), basal lamina (BL), muscle $(\mathrm{m})$, regenerative cell $(\mathrm{Rc})$ and nucleus $(\mathrm{N})(\mathrm{x} 2,200)$

peared. The nuclei were elongated and filled with clumped chromatin. At this stage we observed an extraordinary amount of mitochondria spread throughout the cytoplasm (Fig. 13).

5 days after bloodmeal - The epithelium displayed the rough endoplasmatic reticulum with its typical whorled appearance, in some areas of the anterior section, as observed in sand flies right after emergence (Figs 4 and 14). The basal membrane is undulated, and the basal labyrinths are clearly 
visible (Fig. 14). In the posterior section, the microvilli are arranged in parallel, with a large number of mitochondria and some lipid inclusions. Huge clear vacuoles and lipid inclusions are present at this time, and the basal labyrinths are quite evident (Fig. 15a, b).

Morphometric evaluation - Tables I and II summarize the morphometric results for anterior and posterior sections of the midgut, respectively. Microvilli in cells of the anterior section of the midgut in females, both unfed and after bloodmeal, showed that the major and minor axis are equal indicating that this structure had a predominantely round aspect. However, in fasting insects, the form factor indicated a more circular appearance in this phase than in 12 fed insects. The area of the microvilli are the same in both cases.
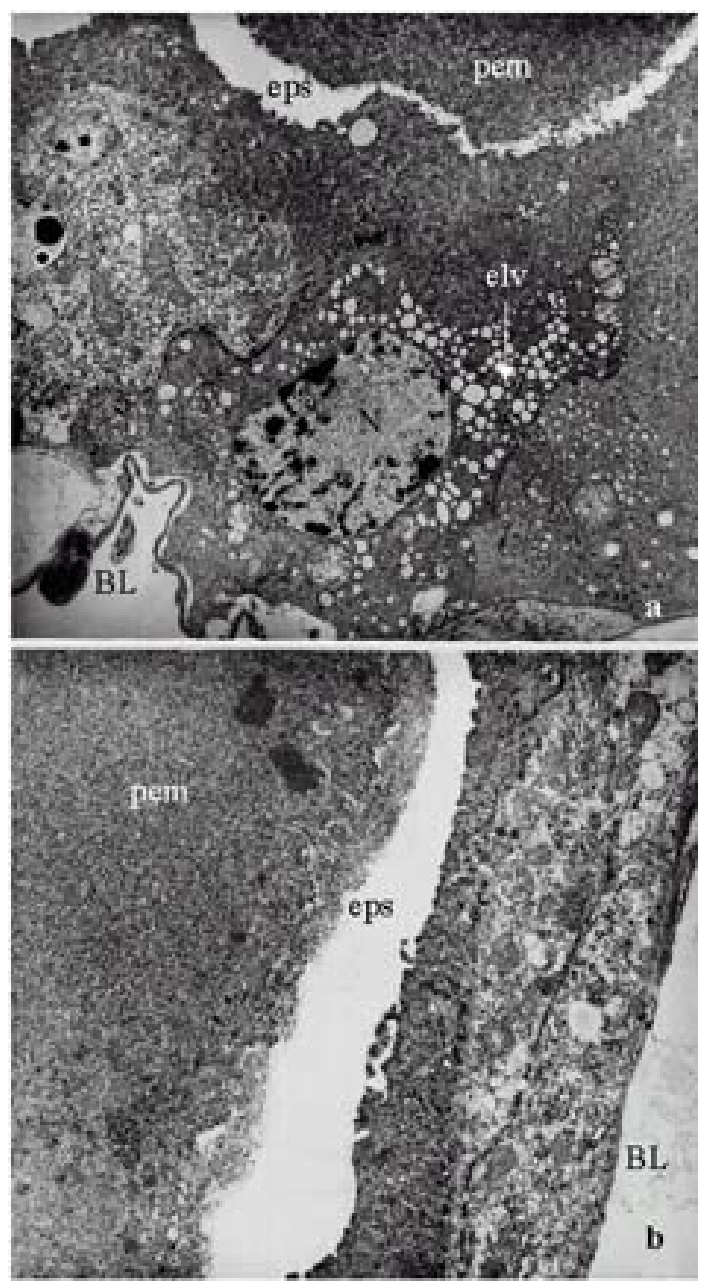

Figs. 11a, b: electron micrograph of a longitudinal section of the posterior midgut region of Lutzomyia intermedia female, $48 \mathrm{~h}$ after bloodmeal. Ectoperitrophic space (eps) more large, peritrophic membrane (pem), electron-lucid vaculoes (elv) around the nucleous (N) and basal lamina (BL) $(\mathrm{x} 1,500)$

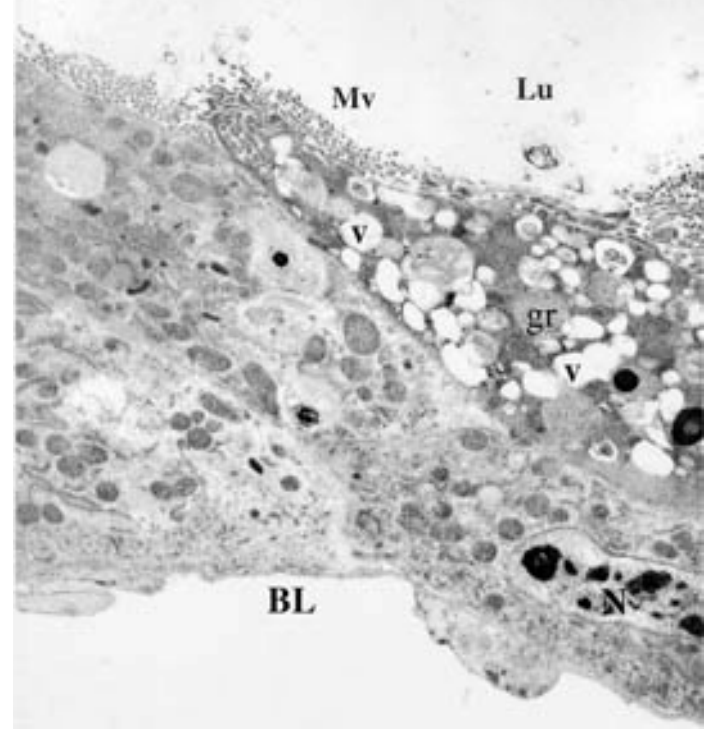

Fig. 12: electron micrograph of a transverse section of the anterior midgut region of Lutzomyia intermedia female, $72 \mathrm{~h}$ after bloodmeal. Lumem (Lu), many clean vacuoles (v), granules (gr) near the microvillis $(\mathrm{Mv})$, nucleus $(\mathrm{N})$ and basal lamina (BL) (x 2,200)

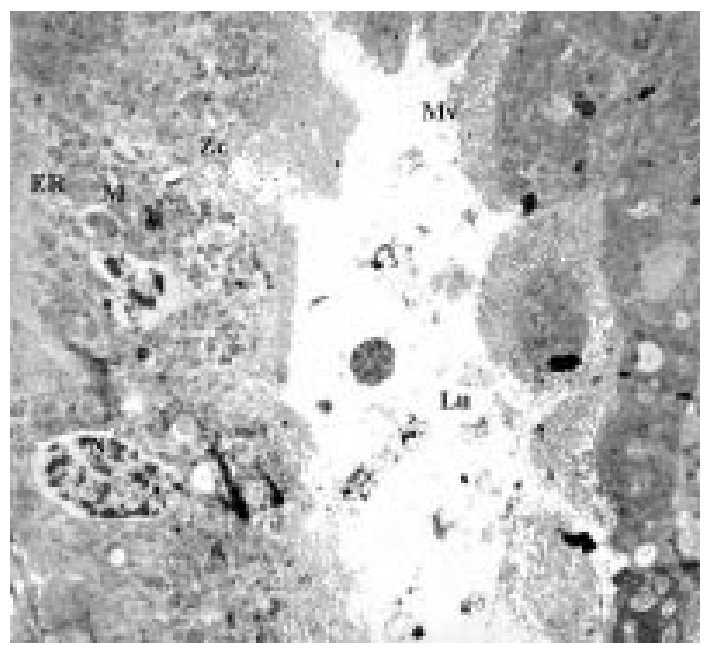

Fig. 13: electron micrograph of a longitudinal section of the posterior midgut region of Lutzomyia intermedia female, $72 \mathrm{~h}$ after bloodmeal showing, lumem (Lu) with bloodmeal digestion residual, microvilli (Mv), mitochondria (M), endoplasmic reticulum (ER) spread for all over the cytoplasm, more nucleus $(\mathrm{N})(\mathrm{x} 3,800)$

In cells of the posterior section, the major axis of the microvilli in unfed insects is almost twice as much as those after the bloodmeal. The form factor is similar both in the anterior posterior sections of the midgut, but with a slightly higher mean value in unfed specimens. The area of the microvilli in the posterior section is smaller in unfed insects after a bloodmeal. 


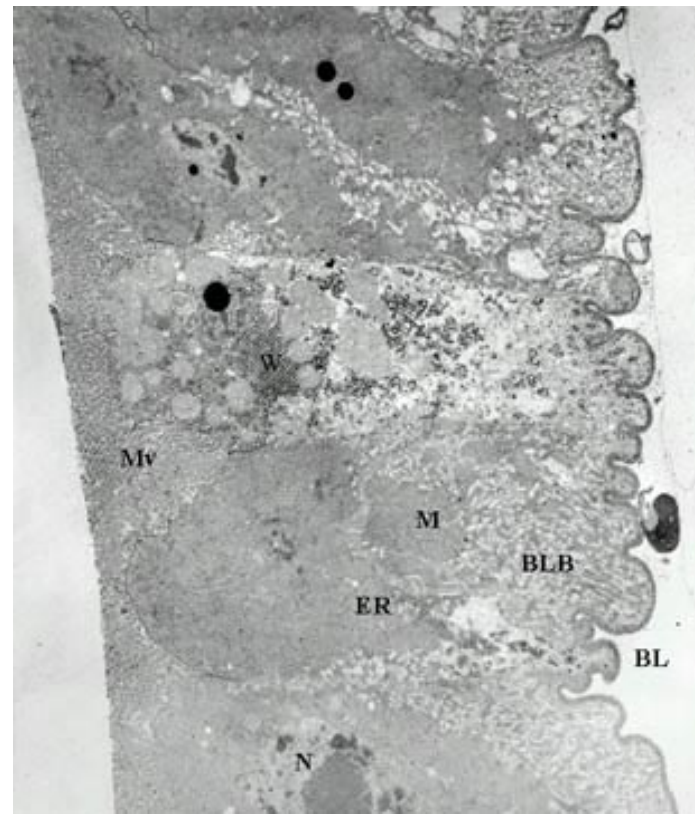

Fig. 14: electron micrograph of a transverse section of the anterior midgut region of Lutzomyia intermedia female, 5 days after bloodmeal showing whorls (W) once again, undulating basal lamina (BL), basal labyrinths in contact with region of the cell apice, microvillis (Mv) and mitochondrias (M) (x 2,800)

The mitochondrial area in cells of the anterior section (Table I) of the midgut is similar under the two experimental conditions, although slightly larger in unfed insects (mean values); the form factor is circular in both cases. However, the major axis of the mitochondria is larger in unfed sand flies. This indicates that during fasting the mitochondria in the epithelium of the anterior section are slightly larger than in insects following a bloodmeal.

In the epithelium of the posterior section (Table II) from unfed females, the mitochondria are approximately twice large as those from females after a bloodmeal. In this investigation, this is true for both the major and minor axis in the mitochondria. The area of the mitochondria in this section, after a bloodmeal, is much smaller than in unfed specimens.

The area occupied by the cell nucleus in the anterior (Table I) and posterior sections (Table II) of the midgut, after a bloodmeal, is larger than in unfed specimens.

\section{DISCUSSION}

In this study, we observed that the midgut of $L$. intermedia displed morphologically well-defined sections under SEM analysis, with a tubular anterior section and a more clearly dilated posterior section. Externally, we observed circular and longitu-
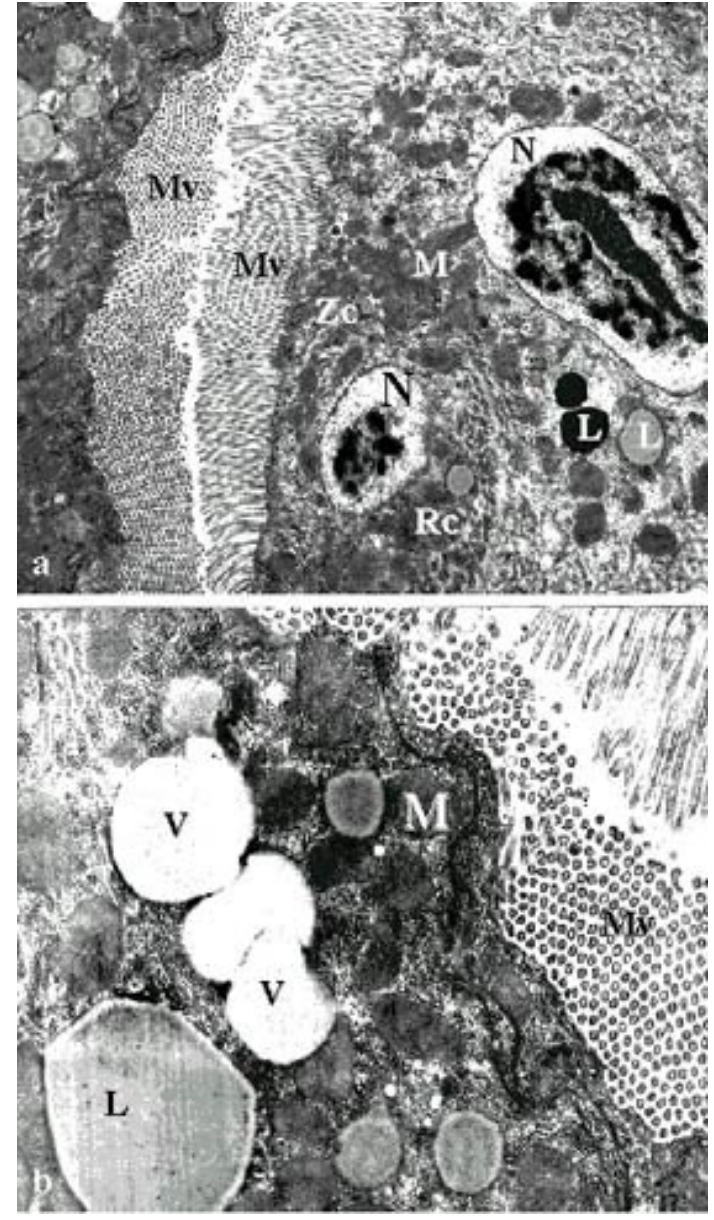

Figs 15a, b: electron micrograph of a longitudinal section of the posterior midgut region of Lutzomyia intermedia female, 5 days after bloodmeal showing microvilli (Mv), regenerative cell $(\mathrm{Rc})$, nucleus $(\mathrm{N})$, mitochondria $(\mathrm{M})$, lipidic inclusions (L) (x 1,900)

dinal musculature in the midgut. As for histological aspects, our observations of the midgut epithelium in L. intermedia are compatible with those described by other authors (Gemetchu 1974, Romoser 1996) for both the anterior and posterior sections.

The description of the midgut epithelium provided by Romoser (1996), based on TEM for fasting hematophagous insects, showed that the apical end of the cell contains microvilli providing an enormous surface area for absorbing material from the lumen. A mucopolysaccharide layer is adhered to the surface of the plasma membrane, forming the glucocalyx. Underneath the columnar cell layer, demarcating the epithelium, was the basal lamina, made up of a complex web of invaginations called basal labyrinths which, like the microvilli, provides 
TABLE I

Morphometrical evaluation of anterior section of the midgut cells of Lutzomyia intermedia

\begin{tabular}{|c|c|c|c|c|c|c|}
\hline & \multicolumn{3}{|c|}{ Unfed } & \multicolumn{3}{|c|}{$12 \mathrm{~h}$} \\
\hline & $\begin{array}{c}\text { Area } \\
\left(\mu \mathrm{m}^{2}\right)\end{array}$ & $\begin{array}{c}\text { Major axis } \\
(\mu \mathrm{m})\end{array}$ & $\begin{array}{c}\text { Minor axis } \\
\quad(\mu \mathrm{m})\end{array}$ & $\begin{array}{c}\text { Area } \\
\left(\mu \mathrm{m}^{2}\right)\end{array}$ & $\begin{array}{c}\text { Major axis } \\
(\mu \mathrm{m})\end{array}$ & $\begin{array}{c}\text { Minor axis } \\
\quad(\mu \mathrm{m})\end{array}$ \\
\hline Microvilli & $0.00-0.12$ & $0.05-1.15$ & $0.05-0.19$ & $0.00-0.11$ & $0.25-1.15$ & $0.05-0.25$ \\
\hline Mitochondria & $0.01-0.33$ & $0.15-1.15$ & $0.13-0.63$ & $0.00-0.23$ & $0.20-0.88$ & $0.13-0.43$ \\
\hline Nucleus & 3.16 & Not determined & Not determined & 5.16 & Not determined & Not determined \\
\hline Mean \pm SD & $0.04-0.03$ & $0.46-0.28$ & $0.13-0.03$ & $0.06-0.03$ & $0.89-0.14$ & $0.14-0.04$ \\
\hline
\end{tabular}

System KS 400 (Kontron Eletronik)

TABLE II

Morphometrical evaluation of posterior section of the midgut cells of Lutzomyia intermedia

\begin{tabular}{|c|c|c|c|c|c|c|}
\hline & \multicolumn{3}{|c|}{ Unfed } & \multicolumn{3}{|c|}{$12 \mathrm{~h}$} \\
\hline & $\begin{array}{l}\text { Area } \\
\left(\mu \mathrm{m}^{2}\right)\end{array}$ & $\begin{array}{l}\text { Major axis } \\
\quad(\mu \mathrm{m})\end{array}$ & $\begin{array}{l}\text { Minor axis } \\
\quad(\mu \mathrm{m})\end{array}$ & $\begin{array}{c}\text { Area } \\
\left(\mu \mathrm{m}^{2}\right)\end{array}$ & $\begin{array}{l}\text { Major axis } \\
(\mu \mathrm{m})\end{array}$ & $\begin{array}{l}\text { Minor axis } \\
(\mu \mathrm{m})\end{array}$ \\
\hline Microvilli & $0.00-0.21$ & $0.00-1.70$ & $0.06-0.23$ & $0.00-0.07$ & $0.05-0.95$ & $0.02-0.19$ \\
\hline Mitochondria & $0.48-0.41$ & $0.30-2.70$ & $0.25-1.15$ & $0.00-0.27$ & $0.05-1.15$ & $0.13-0.43$ \\
\hline Nucleus & 2.21 & Not determined & Not determined & 3.83 & Not determined & Not determined \\
\hline Mean \pm SD & 0.48 & $0.99-0.54$ & $0.61-0.22$ & $0.08-0.05$ & $0.46-0.19$ & $0.24-0.07$ \\
\hline
\end{tabular}

System KS 400 (Kontron Eletronik)

a large surface across which materials can also be transported. Mitochondria are found in some areas of the cytoplasm, many of them associated with the basal labyrinths. The basal lamina may appear granular or have distinct "lattice" type structures. Laterally, in the apical half of the cell, we find an intercellular junction called the continuous zonule. In the basal region, we found spaces demarcated by their membranes, commonly called basal labyrinths. Abundant rough endoplasmatic reticulum was generally seen, which was to be expected of a cell with intensely active synthesis for export.

Regenerative cells have been found at the base of midgut epithelial cells in dipterans (Priester 1971, Hecker 1977, Brown et al. 1985, Glättli et al. 1987, Billingsley 1990), actively secreting enzymes and absorbing alimentary material. When cells in the midgut lining die, the regenerative cells differentiate, taking over all the cell activity.

We observed all the structures cited by Romoser (1996), with no morphological differences according to the method employed, except for the "lattice" type structures and the Golgi apparatus. This may have occurred because a proper technique to display them was not employed. However, the Golgi apparatus has already been demonstrated in the cells of other dipterans (Bertram \& Bird 1961, Priester 1971, Hecker et al. 1971, 1974, 1977, Gemetchu 1974, Rudin \& Hecker 1982, Billingsley 1990). According to Richards (1975) in his studies on the Golgi complex in hematophagous insects, this structure is not as evident as other organelles in the epithelial cells, suggesting that it is poorly developed close to the nucleus. However, some authors have reported the absence of the Golgi apparatus (Waterhouse \& Wright 1960). The smooth endoplasmatic reticulum was not observed in this studies as in other dipterans, but is not an easy structure to find (Bertram \& Bird 1961, Priester 1971, Hecker et al. 1971, 1974, Hecker 1977, Gemetchu 1974, Rudin \& Hecker 1982, Billingsley 1990).

Bertram and Bird (1961) analyzed the fine structure of the midgut under different physiological conditions in Aedes aegypti females and observed that unfed females have a kind of coiled rough endoplasmatic reticulum which they call "whorls", and that after the bloodmeal this structure spread around the cell cytoplasm and underwent clear morphological changes as a result. The authors suggested that the rough endoplasmatic reticulum might be responsible for all the secretory and absorptive functions ascribed to the midgut. It was also in the 60s that Stäubli et al. (1966) demonstrated ultrastructural differences in the posterior section of the midgut in Aedes and Anopheles, including the whorled shape of the rough endoplasmatic reticulum in both the genera they investigated.

These studies on $L$. intermedia confirmed the presence of a rough endoplasmatic reticulum similar to those previously described.

According to Hecker et al. (1971), recently emerged Ae. aegypti females did not display differ- 
entiated organelles and structures in the cells of the posterior section of the midgut epithelium. At this stage, various organelles including the rough endoplasmatic reticulum, mitochondria, and lysosomes are found in formation. Likewise, neither the microvilli nor the basal labyrinths (both of which play important roles in the absorption and transport of substances) had reached their definitive form at this stage. Such precarious development in organelles and structures of the epithelial cells in recently emerged mosquitoes may explain their limited appetite for blood in the first few hours of life, as observed in various species (Consoli \& Williams 1981, Porter 1986, Grossman \& LourençoOliveira 1996).

This may be why L. intermedia females did not feed on blood immediately after emergence, even though it was observed that other cell structures, such as the microvilli, mitochondria, and nuclei in the anterior section of the midgut, were apparently well defined. However, in the posterior section, the basal labyrinths and mitochondria are still not visible. Microvilli appear in both sections, arranged in parallel, differently to that observed by Perfiliev (1928), who found microvilli only in the posterior section of the midgut in Phlebotomus sergenti. Gemetchu (1974), analyzing the fine structure of the midgut in P. longipes females, found microvilli in both sections of the midgut. However, in the posterior section, the latter author only found the whorled rough endoplasmatic reticulum beginning four days after emergence.

Studies on mosquitoes (Bertran \& Bird 1961, Staübli et al. 1966 Hecker et al. 1971) suggest that cell structure development in the posterior section occurs soon after birth, differently than in sand flies, as in the case of $P$. longipes females. Likewise, in $L$. intermedia some structures in the posterior section of the midgut were not well defined soon after emergence, although a discrete whorled rough endoplasmatic reticulum could be observed.

Hecker (1977) compared the anterior and posterior regions of the midgut in anopheline and culicine females. In all the species investigated, the cell structure suggested that both sections of the midgut performed synthesis, secretion, absorption, and transport. In addition, the microvilli are more abundant in the epithelium of the anterior section, with highly dense membranes of the endoplasmatic reticulum and the basal labyrinth. The posterior section was characterized again as having more rough endoplasmatic reticulum and mitochondria than the anterior. Hecker states that absorption of solutions containing carbohydrates and formation of mucous type material occur in the anterior section of the midgut, and that the cells in the posterior section are responsible for synthesis and se- cretion of the peritrophic matrix and digestive enzymes, in addition to being involved in the absorption, transport, and temporary storage of metabolites resulting from blood digestion by the mosquitoes.

As observed by Hecker et al. $(1971,1974)$ and Hecker (1977) in Anopheles and Aedes species, in $L$. intermedia, the anterior section of the midgut may only serve as a region for passage of the bloodmeal, processing only sugar nutrients, leaving blood digestion exclusively to the posterior section.

Rudin and Hecker (1979), analyzing the functionality of the posterior section of the midgut in engorged L. longipalpis females, concluded that in the first $10 \mathrm{~h}$ of blood digestion, the rough endoplasmatic reticulum uncoils, the size of the Golgi zones increases, and the basal labyrinths expand, coinciding with the process of synthesis and secretion of the peritrophic matrix, esterases, and lipases. From 10 to $20 \mathrm{~h}$ after the bloodmeal, the cell structures increase significantly, indicating intense synthesis and secretory activity. After 20 to $30 \mathrm{~h}$, the cell structures showed intense involvement of synthesis and secretion, along with maximum protease activity, increasing the surface area of the microvilli. Prominent lipid inclusions and glycogen deposits during this phase suggest an increase in absorption, storage, and transport. After 30 to 36 $\mathrm{h}$, structures that had been responsible for synthesis and secretion slowly changed their function and began to store and transport nutrients. Finally, after 36 to $72 \mathrm{~h}$, the cell apparatus was reduced along with the end of the digestive cycle. Lipid inclusions and glycogen deposits disappeared from the posterior region.

The observations in L. intermedia are in agreement with the above description, showing that the blood digestion process lasts for over $72 \mathrm{~h}$ and may reach 4 days. A completely clear lumen was observed on the fifth day after the bloodmeal. However, lipid inclusions were already observed in the anterior section in the first few hours after birth, suggesting high storage activity just prior to pupation, since pupae do not feed and the recentlyemerged insects were totally unfed.

The peritrophic matrix was seen $12 \mathrm{~h}$ after the bloodmeal, surrounding the alimentary bolus and performing its function of protecting the epithelium. However, Gemetchu (1974) was only able to detect it in P. longipes $24 \mathrm{~h}$ after the bloodmeal. Twelve hours after the bloodmeal we observed the microvilli in the posterior section of the midgut with electron-lucid profiles, with an electron-lucid space higher up, as observed by Walters (1993) in $P$. perniciosus, suggesting that the digestive process is beginning. Forty-eight hours after the bloodmeal, 
this electron-lucid band increased considerably, and $72 \mathrm{~h}$ after the bloodmeal, its microvilli were totally visible and the peritrophic matrix was no longer seen.

Morphometric analysis of some structures of the midgut epithelial cells, indicated that the nuclei, microvilli, and mitochondria are altered in the midgut epithelium of females after the bloodmeal. Although mithocondria were larger in unfed insects, these organelas display similar profiles in both fed and unfed flies. However, this conclusion is limited to a certain extent by the fact that not all cross-sections analyzed presented nuclear profiles, which limited the sampling and thus the morphometric analysis of these structures. In their studies on the midgut epithelium of $L$. longipalpis, Rudin and Hecker (1982) had already identified morphometric variations in various cell structures of females after the bloodmeal. As in L. intermedia, their experiments identified alterations in the nuclei, mitochondria, and microvilli.

Several morphometric studies have also been performed on the midgut epithelium of Culicidae, showing similarities in the morphological and dimensional changes associated with the digestive process (Hecker 1977, Bauer et al. 1977, Rudin \& Hecker 1979).

\section{ACKNOWLEDGMENTS}

To Dr Aloísio Falqueto, University Federal from Espírito Santo, Brazil, for help in the field work and to Mr Gerneval Luciano Batista and Mr Bruno Ávila for technical support.

\section{REFERENCES}

Adler S, Theodor O 1926. The mouth parts, alimentary tract, and salivary apparatus of the female in Phlebotomus papatasi. Ind J Med Res 29: 803-400.

Angermüller S, Fahimi HD 1982. Imidazole-buffered osmium tetroxide: an excellent stain for visualization of lipids in transmission electron microscopy. Histochem J 14: 823-835.

Aragão HB 1922. Transmissão de leishmaniose no Brasil pelo Phlebotomus intermedius. Bras Med 36: 129130.

Bauer P, Rudin W, Hecker H 1977. Ultrastructural changes in midgut cells of female Aedes aegypti L. (Insecta, Diptera) after starvation or sugar diet. Cell Tiss Res 177: 215-219.

Bertram SD, Bird GD 1961. Studies on mosquito-borne viruses in their vectors. I. The normal fine structure of the midgut epithelium of the adult female Aedes aegypti (L.) and the functional significance of its modification following a blood meal. Trop Med Hyg 55: 404-411.

Billingsley PF 1990. The midgut ultrastructure of hematophagous insects. Ann Rev Entomol 35: 219-248.

Blackburn K, Wallbanks KR, Molyneux DH, Havin DR, Winstanley SL 1988. The peritrophic membrane of the female sandfly Phlebotomus papatasi. Ann Trop
Med Parasitol 82: 613-619.

Brown WR, Raikhel AS, Lea AO 1985. Ultrastructure of midgut endocrine cells in the adult mosquito, Aedes aegypti. Tissue Cell 17: 709-721.

Consoli RAGB, Williams P 1981. Aspects of the biology of laboratory-reared female Aedes fluviatilis. Mosq News 19: 151-155.

Davis NT 1967. Leishmaniasis in the Sudan Republic. 28. Anatomical studies on Phlebotomus orientalis Parrot and P. papatasi Scopoli (Diptera: Psychodidae). J M Entomol 4: 50-65.

Elnaiem DA, Ward RD, Young PE 1994. Development of Leishmania chagasi (Kinetoplastida: Trypanosomatidae) in the second blood-meal of its vector Lutzomyia longipalpis (Diptera: Psychodidae). Parasitol Res 80: 414-419.

Elnaiem DA, Ward RD, Young PE 1992. An ultrastructural study on the early development of Leishmania chagasi (Kinetoplastida: Trypanosomatidae) in its vector Lutzomyia longipalpis (Diptera: Psychodidae). Ann Parasitol Hum Comp 67: 3-8.

Forattini OP 1973. Entomologia Médica, 40 vol., Editora Blücher Ltda., São Paulo, 658 pp.

Forattini OP, Santos MR dos 1952. Nota sobre infecção natural de Phlebotomus intermedius Lutz \& Neiva, 1912, por formas em leptomonas, em um foco de leishmaniose tegumentar americana. Archos Hig Saúde Públ 17: 171-174.

Forattini OP, Pattoli DBG, Rabello EX, Ferreira OA 1972. Infecção natural de flebotomíneos em foco enzoótico de leishmaniose tegumentar no Estado de São Paulo, Brasil. Rev Saúde Pública 6: 431-433.

Gemetchu T 1974. The morphology and fine structure of the midgut and peritrophic membrane of the adult female, Phlebotomus longipes Parrot and Martin (Diptera: Psychodidae). Ann Trop Med Parasitol 68: 111-124.

Glättli E, Rudin W, Hecker H 1987. Immunoelectron microscopic demonstration of pancreatic polypeptide in midgut epithelium of hematophagous dipterans. J Histochem Cytochem 35: 891-896.

Grosman GA, Lourenço-de-Oliveira R 1996. Observações sobre a emergência, longevidade, alimentação sangüínea e oviposição de Culex saltanensis Dyar, em laboratório (Diptera, Culicidae). Revta Bras Ent 40: 357-365.

Hecker H 1977. Structure and function of midgut epithelial cells in Culicidae mosquitoes (Insecta, Diptera). Cell Tiss Res 184: 321-341.

Hecker H, Brun R, Reinhardt C, Burri PH 1974. Morphometric analysis of the midgut of female Aedes aegypti (Insecta, Diptera) under various physiological conditions. Cell Tiss Res 152: 31-49.

Hecker H, Freyvogel T.A, Briegel, Steiger R 1971. Ultrastructural differentiation of the midgut epithelium in female Aedes aegypti (L.) (Insecta, Diptera) imagines. Acta Trop 28: 80-104.

Killick-Kendrick R, Wallbanks FR, Molyneux DH, Lavin DR 1988. The ultrastructure of Leishmania major in the foregut and proboscis of Phlebotomus papatasi. Parasitol Res 74: 586-590.

Lainson R, Shaw JJ 1968. Leishmaniasis in Brazil. I. 
Observations on enzootic rodent leishmaniasis-incrimination of Lutzomyia flaviscutellata (Mangabeira) as the vector in the lower Amazonian basin. Trans $R$ Soc Trop Med Hyg 62: 385-395.

Molyneux DH, Killick-Kendrick R, Ashford RW 1975. Leishmania in phlebotomine sandflies. III The ultrastructure of Leishmania mexicana amazonensis in the midgut and pharynx of Lutzomyia longipalpis. Proc $R$ Soc London B 190: 341-357.

Perfiliev PP 1928. Zur vergleichenden Anatomie von Phlebotomus. Zeitschr f Parasitenk I: 437-475.

Porter CH 1986. Intervals to blood feeding following emergence and oviposition in Aedes triseriatus (Diptera: Culicidae). J Med Ent 23: 222-224.

Priester W 1971. Ultrastructure of the midgut epithelial cells in the fly Callifora erythrocephala. J Ultrastructure Res 36: 783-805.

Rangel EF, Azevedo ACR, Andrade CA, Souza NA, Wermelinger ED 1990. Studies on sandfly fauna (Diptera: Psychodidae) in the focus of cutaneous leishmaniasis in Mesquita, Rio de Janeiro State, Brasil. Mem Inst Oswaldo Cruz 85: 39-45.

Rangel EF, Barbosa AF, Andrade CA, Souza NA, Wermelinger ED 1992. Development of Leishamania (Viannia) brasiliensis Vianna, 1911 in Lutzomyia intermedia (Lutz \& Neiva, 1912) under experimental conditions. Mem Inst Oswaldo Cruz 87: 235238.

Rangel EF, Souza NA, Wermelinger ED, Barbosa AF 1984. Infecção natural de Lutzomyia intermedia (Lutz \& Neiva, 1912) em área endêmica de leishmaniose tegumentar no Estado do Rio de Janeiro. Mem Inst Oswaldo Cruz 79: 395-396.

Rangel EF, Souza NA, Wermelinger ED, Barbosa AF 1985. Estabelecimento de colônia, em laboratório, de Lutzomyia intermedia (Lutz \& Neiva, 1912) (Diptera: Psychodidae: Phlebotominae). Mem Inst Oswaldo Cruz 80: 219-226.

Reynolds ES 1963. The use of lead citrate at high $\mathrm{pH}$ as na electron-opaque stain in electron microscopy. $J$ Histochem Cytochem 17: 208-212.
Richards GA 1975. The ultrastructure of the midgut of hematophagous insects. Acta Trop 32: 83-95.

Romoser WS 1996. The Biology of Disease Vectors, University Press of Colorado, $606 \mathrm{pp}$.

Rudin W, Hecker H 1979. Functional morphology of the midgut of Aedes aegypti L. (Insecta, Diptera) during blood digestion. Cell Tissue Res 200: 193-203.

Rudin W, Hecker H 1982. Functional morphology of the midgut of a sandfly as compared to other hematophagous nematocera. Tissue Cell 14: 751-758.

Stäubli W, Freyvogel TA, Suter J 1966. Structural modification of the endoplasmic reticulum of the midgut epithelial cells of mosquitoes in relation to blood intake. J Microscopy 5: 189-204.

Walters LL 1993. Leishmania differentiation in natural and unnatural sandfly hosts. J Euk Microbiol 40: 196-206.

Walters LL, Chaplin GL, Mobi GB, Tesh RB 1989a. Ultrastructural biology of Leishmania (Viannia) panamensis (=Leishmania braziliensis panamensis) in Lutzomyia gomezi (Diptera: Psychodidae): a natural host-parasite association. Am J Trop Med Hyg 40: 19-39.

Walters LL, Irons KP, Modi GB, Tesh RB 1992. Refractory barriers in the sandfly Phlebotomus papatasi (Diptera: Psychodidae) to infection with Leishmania panamensis. Am J Trop Med Hyg 46: 211-228.

Walters LL, Modi GB, Chaplin GL, Tesh RB 1989b. Ultrastructural development of Leishmania chagasi in its vector, Lutzomyia longipalpis (Diptera: Psychodidae). Am J Trop Med Hyg 41: 295-317.

Walters LL, Modi GB, Tesh RB, Burrage T 1987. Hostparasite relationship of Leishmania mexicana mexicana and Lutzomyia abonnenci (Diptera: Psychodidae). Am J Trop Med Hyg 36: 294-314.

Warburg A, Hamada GS, Schlein Y, Shire D 1986. Scanning electron microscopy of Leishmania major in Phlebotomus papatasi. Z Parasitenkd 72: 423-431.

Waterhouse DF, Wright M 1960. The fine structure of the mosaic epithelium of blowfly larvae. J Insect Physiol 5: 230-239. 
1152 Features of Midgut of L. intermedia - Cláudia A Andrade-Coêlho et al. 